\title{
DA TRADIÇÃO CRÍTICA: OTTO MARIA CARPEAUX
}

\author{
APRESENTAÇÃO DE IEDA LEBENSZTAYN \\ Universidade de São Paulo \\ São Paulo, São Paulo, Brasil
}

Como Otto Maria Carpeaux, aliás Otto Karpfen, nascido em Viena em 1900 e chegado ao Brasil em agosto de 1939, aprendeu em pouco tempo a língua portuguesa?

"Todos os cemitérios se parecem." Tal o poder de concentrar uma filosofia em poucas palavras, essa frase, com que Machado de Assis encerra a crônica "O velho Senado" (1898), atraiu o crítico austríaco para a língua e a literatura brasileiras. Mas isso foi no verão de 1938, em Bruxelas, depois de Karpfen haver encontrado num sebo um pequeno volume amarelo e se deliciar com trechos traduzidos para o francês dessa velha antologia da literatura brasileira: "Vale a pena aprender a língua portuguesa!". Mal sabia ele que o pensamento de então se realizaria, e no Brasil, no Rio de Janeiro, para onde viria em companhia da mulher, Helena, fugindo do nazismo. Em 1941 Carpeaux já escrevia as primeiras páginas no idioma aprendido com quase quarenta anos. Sem professor nem aula, muita leitura, sobretudo de Machado de Assis, ensinou a língua portuguesa a Otto Maria Carpeaux. E irmanando-se, apesar das diferenças, a grandes leitores como Mário de Andrade e Carlos Drummond de Andrade, o crítico declara que chegou a amar Machado, como se ama "o vinho da verdade que embriaga".

O relato desse encontro de Carpeaux com o pensamento, a língua e a terra natal de Machado de Assis se lê em "Depoimento machadiano", publicado no Correio da Manhã, do Rio de Janeiro, a 27 de setembro de 1958. ${ }^{1}$ Machado está

\footnotetext{
${ }^{1}$ Também em conversa com Graciliano Ramos, Carpeaux declara sua admiração por esse texto de Machado: "A última página do 'Velho Senado' afigura-se-me como a maior página de prosa portuguesa escrita no Brasil" (Cf. CARPEAUX, Otto Maria. Obras-primas desconhecidas do conto brasileiro. A Manhã, Rio de Janeiro, 10 abr. 1949. In: RAMOS, Graciliano. Conversas. Rio de Janeiro: Record, 2014).

"O velho Senado", de Machado de Assis, foi publicado originalmente na Revista Brasileira, do Rio de Janeiro, em 1898. Em entrevista a Homero Senna, de 1949, Carpeaux revela terem sido as Páginas recolhidas, de Machado de Assis, o primeiro livro brasileiro que leu, e "O velho Senado" "a maior página" que leu em prosa portuguesa (SENNA, Homero. A literatura brasileira vista por um europeu. In: República das Letras: 20 entrevistas com escritores. 3. ed. rev. e atualizada. Rio de Janeiro: Civilização Brasileira, 1996, p. 301).
} 
presente em diversos ensaios de Carpeaux: são reflexões a respeito de sua literatura, resenhas de livros centrados em sua obra ou vinculados a ela, além de artigos em que o evoca. Observem-se estes títulos, alguns inéditos em livro: ${ }^{2}$ "Uma fonte da filosofia de Machado de Assis" (A Manhã, 1948); "A descoberta de Machado de Assis" (Folha da Manhã, 1952); "A fortuna de Machado" (O Jornal, 1954); "Possibilidades da crítica" (O Jornal, 1955); "Verdades sobre Machado" (O Jornal, 1955); "Leituras e comentários" (O Jornal, 1955); "Ideias brasileiras" (Correio da Manhã, 1956); "Machado e outros cariocas" (Correio da Manhã, 1957); "Em torno de um monumento" (Correio da Manhã, 1958); "Várias histórias" (O Estado de S. Paulo, 1958); "Machado e Bandeira" (Correio da Manhã, 1959); "Tradição e revolução" (Correio da Manhã, 1959); "De novo sobre Machado" (O Globo, 1961).

Como se nota, Carpeaux colaborou bastante na imprensa dos anos 1940 aos 60, trabalhando em especial no Correio da Manhã, em que foi acolhido pelo crítico Álvaro Lins. Contou com a amizade de intelectuais e artistas como Aurélio Buarque de Holanda, José Lins do Rego, Graciliano Ramos, Augusto Frederico Schmidt. Destacam-se, entre outras publicações: a Pequena bibliografia crítica da literatura brasileira (1949); a História da literatura ocidental (oito volumes, de 1958 até 1966); Uma nova história da música (1958). A partir dos anos 1960, deixou o ensaísmo literário, para escrever, em jornais clandestinos, artigos de combate à ditadura militar. ${ }^{3}$ Faleceu no Rio de Janeiro, a 3 de fevereiro de 1978.

Sugestivo desde o título, "Ideias brasileiras" é o ensaio de Otto Maria Carpeaux escolhido para este número de Machado de Assis em Linha. Trata-se de uma resenha do livro Contribuição à história das ideias no Brasil, de João Cruz Costa (São Paulo, 1904 - São Paulo, 1978), publicado pela José Olympio em 1936, na Coleção Documentos Brasileiros, dirigida por Octávio Tarquínio de Souza.

Existe uma filosofia no Brasil? - essa é a indagação com que Carpeaux, lendo Cruz Costa, evoca Machado de Assis, que cumpriu tal papel ao transformar o caos em cosmos. Um dos responsáveis pela criação do Departamento de Filosofia da então FFCL da Universidade de São Paulo, Cruz Costa foi professor dessa

\footnotetext{
2 Vários desses textos, inclusive o que será aqui apresentado, foram localizados, no Arquivo Museu de Literatura Brasileira da Fundação Casa de Rui Barbosa, por Hélio de Seixas Guimarães, durante seu estágio de pós-doutorado nessa instituição, entre agosto de 2016 e abril de 2017.

3 Cf. BOSI, Alfredo. Relendo Carpeaux. Estudos Avançados, São Paulo, v. 27, n. 78, p. 279-290, 2013. Disponivel em: http:/www.scielo.br/scielo.php?script=sciarttext\&pid=S0103$40142013000200018 \& \operatorname{lng}=e n \& n r m=$ iso. Acesso em: $1^{\circ}$ nov. 2016.
} 
faculdade de 1951 a 1965. Em entrevista publicada na revista Trans/Form/Ação em 1975,4 é Machado o escritor brasileiro referido por Cruz Costa ao recordar as leituras de sua formação nos anos 1920. Sendo seu propósito estimular nos alunos a reflexão crítica sobre a realidade brasileira, significativamente Cruz Costa teve Antonio Candido como discípulo na faculdade. E é conhecida a observação deste, segundo a qual, no Brasil, diversamente de outros países, as melhores expressões "do pensamento e da sensibilidade" 5 quase sempre couberam à literatura, mais do que à filosofia e às ciências humanas. Antonio Candido destaca evidentemente Machado de Assis, além de José de Alencar, Graciliano Ramos, Gonçalves Dias, Castro Alves, Mário de Andrade, Joaquim Nabuco, Euclides da Cunha e Gilberto Freyre.

Já se vê que o ensaio de Otto Maria Carpeaux convoca a melhor tradição do olhar crítico brasileiro, formada ante os impasses de um país profundamente marcado pela experiência colonial. E Machado de Assis está no centro da questão. Se linguagem e pensamento não se dissociam, não é difícil imaginar o quanto Carpeaux se interessou pela arte de Machado e pelos problemas específicos do pensamento brasileiro nela configurados, em suas dimensões psicológicas, históricas, políticas.

Assim, a MAEL 19 convida o leitor para conhecer com Carpeaux a "tarefa filosófica" de Machado de Assis, a qual conquistou o crítico austríaco para a língua portuguesa desde a frase que se fez verso de Drummond:

Todos os cemitérios se parecem, e não pousas em nenhum deles, mas onde a dúvida apalpa o mármore da verdade, a descobrir a fenda necessária; onde o diabo joga dama com o destino, estás sempre aí, bruxo alusivo e zombeteiro, que revolves em mim tantos enigmas. ${ }^{6}$

\footnotetext{
${ }^{4}$ Cf. Entrevista com João Cruz Costa. Trans/Form/Ação, Marília, v. 34, n. spe, p. 107-115, 2011. Disponível em: http://www.scielo.br/scielo.php?script=sciarttext\&pid=S0101-31732011000300005\&lng=en\&nrm=iso. Acesso em: $1^{\circ}$ nov. 2016. Entrevista originalmente publicada na revista Trans/Form/Ação, v. 2, p. 87-94, 1975. ${ }^{5}$ CANDIDO, Antonio. Literatura e cultura de 1900 a 1945 (Panorama para estrangeiros) [1950]. In: Literatura e sociedade. Ensaios de teoria e história literária. São Paulo: Companhia Editora Nacional, 1976, p. 156.

${ }^{6}$ ANDRADE, Carlos Drummond de. A um bruxo, com amor. A vida passada a limpo. In: Obra completa. Rio de Janeiro: Aguilar, 1964, p. 312-313.
} 


\title{
IDEIAS BRASILEIRAS
}

Ensaio originalmente publicado no Correio da Manhã, em 19 de maio de 1956

\author{
OTTO MARIA CARPEAUX
}

JOÃO CRUZ COSTA: Contribuição à história das ideias no Brasil. (O desenvolvimento da filosofia no Brasil e a evolução histórica nacional). Rio de Janeiro, José Olympio, 1936, 484 páginas (Coleção Documentos Brasileiros, 86).

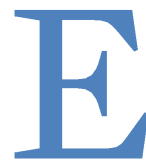

m boa hora, o sr. Octávio Tarquínio de Souza resolveu incluir na Coleção Documentos Brasileiros, que dirige, o trabalho do professor Cruz Costa. Pois, embora não se tratando propriamente de um documento e, sim, de um estudo sobre documentos nunca antes reunidos e tão bem interpretados, o livro oferece documentação inédita e indispensável para a compreensão da evolução histórica do Brasil, à qual o próprio sr. Octávio Tarquínio de Souza já tem dado tantas contribuições valiosas e à qual continua dedicando seu esforço editorial e de mentor.

Professor de filosofia na Universidade de São Paulo, o sr. Cruz Costa pertence a uma nova geração de estudiosos. Oferece-nos um tipo de livro científico assim como o esperávamos há muito. Não começa estudo sobre assunto brasileiro com divagações sobre a pré-história da humanidade ou sobre a história do assunto no mundo greco-romano; em compensação, termina o livro com exaustivas indicações bibliográficas e com índice onomástico em que os autores não aparecem conforme os nomes de batismo. O professor Cruz Costa, como se vê, é um homem civilizado.

Encarregou-se da tarefa de escrever nada menos que a história espiritual inteira de uma nação inteira. Não adotou, propriamente, nenhum dos métodos historiográficos, elaborados pela "Geistesgeschichte" alemã, de Dilthey até Rothacker. Em vez do movimento das ideias, deu-nos a história dos movimentos em torno das ideias. Dois capítulos introdutórios do livro tratam da herança portuguesa e das vicissitudes da nossa formação colonial. Depois, estuda-se a história da filosofia no Brasil durante os séculos XIX e XX. Basta salientar as etapas mais importantes: o ecletismo de Mont'Alverne; o positivismo, que mereceu, com razão, estudo muito pormenorizado, cheio de revelações de fatos 
até agora ignorados ou não bastante focalizados; a Escola do Recife; o espiritualismo de Farias Brito; as ideias de Alberto Torres; o modernismo filosófico de Graça Aranha; o espiritualismo de Jackson de Figueiredo. Parece que não falta nenhum nome ou movimento de alguma importância, com exceção dos pensadores propriamente contemporâneos, das gerações que ainda não se tornaram históricas. Só no futuro será possível estudar com proveito e apreciar a influência, no Brasil, de Ortega y Gasset, da "Geistesgeschichte" alemã, do neotomismo, do existencialismo, do neopositivismo etc.

Dedicou o professor Cruz Costa atenção especial às influências estrangeiras que foram, na verdade, todo-poderosas. Realizou, a esse respeito, trabalho de pioneiro, que não podia ser completo. Ainda não existem estudos especializados sobre a contribuição da diplomacia brasileira para a importação de ideias estrangeiras; que nossos embaixadores e cônsules chegaram a conhecer na Europa. Tampouco foi estudada a influência das revistas estrangeiras, assinadas no Brasil. Seria, porém, espetáculo dos mais interessantes acompanhar o esplendor e a miséria, no Brasil, da Revue des Deux Mondes, substituída depois pelo Mercure de France, substituído depois, por sua vez, pela Nouvelle Revue Française; até chegar a hora de Paris-Match... Espetáculo interessante e melancólico.

Realmente, a melancolia é o sentimento que nos invade, depois da leitura do livro do professor Cruz Costa. Dir-se-ia, com Machado de Assis: "Quanta coisa obsoleta!". Quantas grandes correntes de ideias, aparecendo com a força da maré e deixando, depois, secas estas paragens! E tudo importado! Os espíritos filosoficamente interessados no Brasil acompanharam fielmente a evolução do pensamento estrangeiro durante um século e meio. Mas quando teremos, enfim, a nossa própria filosofia brasileira?

Poder-se-ia observar que nem todas as nações possuem pensamento filosófico autóctone. Nem todas possuem o gênio especificamente especulativo dos gregos ou dos alemães. Nações tão importantes, tão produtivas em outros setores da atividade espiritual como os russos nunca deram ao mundo um grande filósofo. Será que esse fato os diminui, porventura? Será tão indispensável a atitude filosófica? Por que e para que se está, afinal de contas, filosofando?

Dizem que no começo da filosofia está o assombro, a surpresa. Para esclarecer melhor essa antiquíssima frase, convém citar outra, mais moderna: "Ce qui m'étonne, ce n'est pas le désordre, c'est l'ordre". O mundo apresenta-se-nos como desordem, como caos assombroso. Mas o que surpreende, o que é admirável 
é a ordem que o espírito humano consegue impor-lhe, transformando o "chaos" em "kosmos".

A exigência, apresentada a determinada nação ou determinada ração, de produzir filosofia própria, assim como se exige um modo próprio de vida ou a independência política ou uma cozinha nacional, parte de premissa de que aquele caos não é o mesmo nas diferentes partes do mundo. Supõe-se que existe algo como um caos nacional, um caos brasileiro, "nunca antes visto pelos marujos deslumbrados"; concluindo-se que a missão do espírito brasileiro é a de dominar esse caos por um processo especial com resultado especial. E esse resultado especial seria a filosofia brasileira.

Mais outra conclusão: a filosofia europeia não seria capaz de cumprir aquela tarefa, porque já na Europa se teria revelado incapaz de realizar-se, ficando nas nuvens da especulação abstrata. Encontro essa opinião, no Brasil, justamente naqueles que mais foram influenciados pelo pensamento europeu contemporâneo.

Mas será possível "realizar" uma filosofia, qualquer filosofia? A pergunta é antiquíssima. De Platão até Heidegger não deixou ela dormir os filósofos. A única resposta possível, um pouco rude embora, foi dada por Marx, nas Teses sobre Feuerbach: os filósofos sempre têm interpretado de maneiras diferentes o mundo, mas cumpre modificá-lo. Então, sim, algo estará realizado. Mas esse "algo" não será a filosofia, "no es un afán de saber. Es una conducta. Conducta basada em7

Aquela exigência só revela que o caos das influências filosóficas estrangeiras no Brasil ainda não foi bem dominado. A obra do professor Cruz Costa poderá contribuir, metodologicamente, para melhor esclarecimento dos espíritos. Uma dessas contribuições encontra-se em certas subdivisões do livro, cujos títulos inspiram, à primeira vista, estranheza. A parte dedicada ao século XX começa com dois capítulos sobre o "Advento da República" e as "Vicissitudes do regime republicano". Pretende, evidentemente, o autor enquadrar na realidade social da época o pensamento brasileiro. Também pensou na possibilidade de encontrar certas tendências desse pensamento, pouco representadas nas cátedras universitárias, em ideologias de partidos políticos, por mais incertas que sempre tenham sido no Brasil; basta lembrar a existência marginal, neste país, do socialismo. Mas com certa surpresa também encontramos, nos referidos dois capítulos, muitos pormenores sobre candidaturas, vitoriosas ou fracassadas, à presidência da República, sobre quarteladas e rebeliões etc., sobre polêmicas

\footnotetext{
${ }^{7}$ No original, essa frase está assim interrompida. Mas na sequência do texto vêm a citação completa e a referência à autoria de María Zambrano.
} 
intermináveis que dão vontade de gritar, com Mercútio: "A plague o' both your houses!". Nesses capítulos, especialmente, o historiador das ideias no Brasil virou cronista de movimentos sociais (e menos sociais). Mas está certo assim. A política brasileira sempre aproveitou as oportunidades oferecidas pela luta na vida pública para servir-se de argumentos tirados dos últimos livros, chegados da Europa, inclusive dos livros filosóficos. Com a superficialidade da adoção de "Weltanschauungen" e "sistemas" compete a tendência de sua exploração para fins imediatos. Bem disse o boêmio Paula Ney, encontrado em plena rua do Ouvidor com grosso volume alemão debaixo do braço: "Não sei o alemão, mas conheço meu país". Uma das consequências desse imediatismo, intimamente antifilosófico, é a possibilidade de mistura indiscriminada das mais diversas influências estrangeiras e, enfim, um caos espiritual, capaz de causar maior assombro que o da natureza americana, inclusive as florestas amazônicas com seus ruídos inarticulados. Mas, "ce qui m'étonne, ce n'est pas le désordre, c'est l'ordre". Isto é, o fato de que realmente já se conseguiu, no Brasil, dominar esse caos ruidoso, transformando-o em "kosmos" calmamente equilibrado.

Os nomes, os livros, pensamentos e fatos citados pelo professor Cruz Costa são numerosos. Nem sempre são importantes. Os verdadeiros filósofos são raros em toda parte e em todos os séculos; e não dá resultado, quando cabeças de segunda categoria se ocupam com problemas de primeira. Mas, em compensação é possível encontrar ideias autenticamente filosóficas em livros e em autores que nossa "vã filosofia" costuma desclassificar como "apenas" literárias. Assim como foram filósofos o diplomata Machiavelli e o físico Galilei, também foram filósofos o poeta Goethe, o dramaturgo Shakespeare, o romancista Cervantes. O historiador das ideias no Brasil não as achou, porém, nos poetas e romancistas brasileiros, porque neles não as tinha procurado. Concedeu numerosas citações a Rui Barbosa, grande estadista, grande orador e cabeça especificamente a-filosófica. Mas fala menos das ideias que inspiraram os poetas da Inconfidência Mineira. E apenas poucas vezes citado aparece o nome de Machado de Assis.

Parece-me, porém, que nenhum pensador brasileiro, até hoje, estava tão surpreso (ou assombrado ou "étonné") como Machado de Assis, perante o caos do seu ambiente e em sua alma; e que nenhum brasileiro, até hoje, conseguiu tão soberanamente dominar este e aquele. Os romances e os contos de Machado de Assis não formam um tratado, não constituem um sistema de filosofia. Mas neles estão resumidos ou, melhor, "encarnados" os problemas específicos do pensamento brasileiro. Machado de Assis é "filósofo" no sentido em que o povo chama assim, a um homem, seja mesmo de condição humilde, mas cujo espírito é 
capaz de "resistir los azarosos vaivenes de la vida". Sua filosofia "no es un afán de saber. Es una conducta. Conducta basada en ver de los acontecimientos su cara y cruz; en ver la vida como un tapiz al que hay que dar la vuelta. De ahí la sorna, la malícia del buen filósofo. Soporta lo que viene, con entereza, con serenidad comedida, con dignidad sobre todo: parece estoico".

Essas frases, que tomo emprestadas a um livro de María Zambrano sobre "Pensamiento y poesia en la vida española", definem bem a atitude de Machado de Assis: com exceção da última palavra do trecho citado. O Brasil desconhece a tradição do estoicismo, sempre viva na alma espanhola. Mas tampouco é possível filiar Machado a outras correntes da tradição ibérica ou do seu tempo. Nosso Machado é da estirpe dos Sextus Empiricus, dos David Hume: um espírito pirroniano. Por isso sempre inspirou, desde os dias da Escola do Recife, repugnância às cabeças dogmáticas. Sua obra continua cumprindo a tarefa filosófica de semear dúvidas. Não dá soluções. Às vezes, nem responde às nossas perguntas insistentes, entrincheirando-se atrás da máscara do humorismo. Lembra aquele filósofo hindu que, tendo prometido aos seus discípulos a revelação da Suprema Sabedoria, ficou calado; mas quando insistiram, o sábio disse: "A suprema sabedoria é isto mesmo - o silêncio". 